\title{
Early development of executive functions: A differential study
}

\author{
Sylvia Sastre-Riba ${ }^{1 *}$, Eduardo Fonseca-Pedrero ${ }^{1}$ and $\mathrm{M}^{\mathrm{a}}$ Luisa Poch-Olivé ${ }^{2}$ \\ 1 Department of Educational Sciences. University of La Rioja, Spain \\ 2 Hospital San Pedro (La Rioja, Spain)
}

\begin{abstract}
Título: Desarrollo temprano de las funciones ejecutivas: un estudio diferencial.

Resumen: La ontogénesis de las funciones ejecutivas es esencial para explicar el desarrollo típico y atípico. Las funciones ejecutivas deben ser estudiadas desde edades tempranas debido a sus consecuencias sobre la flexibilidad mental, la monitorización de la información, la planificación y el control cognitivo. Proponemos un estudio diferencial en cursos de desarrollo alternativos: bebés típicos, bebés con Síndrome de Down y bebés con factores de riesgo al nacer (hipotiroidismo congénito y bajo peso). Mediante la metodología observacional sistemática se registró la actividad espontánea de los bebés. Los resultados indicaron que: a) los bebés típicos mostraron mayor flexibilidad en su actividad y en el logro de objetivos; b) entre los bebés de riesgo, la menor eficacia ejecutiva se detecta entre los de bajo peso al nacer, en cambio los bebés con hipotiroidismo congénito se situaron más cerca de los bebés típicos, c) los niños con bajo peso al nacer mostraron un buen nivel de combinación de acciones pero menor número de resultados; y d) los bebés con Síndrome de Down mostraron más dificultades de funcionamiento ejecutivo, menor flexibilidad, mayor perseverancia y menor detección de errores.

Palabras clave: Desarrollo temprano; desarrollo diferencial; función ejecu-
\end{abstract} tiva; resultado cognitivo.

\section{Introduction}

Current research considers that the development and functioning of the human mind implies the active interrelationship between genes and the surrounding environment from the outset of mental development (Johnson, 2003). Knowledge of its architecture and functioning requires the ongoing neuroconstructivist research (Westermann et al., 2007) so that researchers can understand how the developing mind (or representational redescription) responds to the growing volume of information and number of action options required in daily life: Control of attention, decision making and coordinated function referred to as "executive control".

Thus, the cognitive functioning of the human mind cannot be studied without taking these functions into account. This question has acquired considerable relevance in neuropsychological research into cognitive development, since these functions can help researchers to explain important aspects of typical and atypical development with their corresponding neurological correlates. They are also essential for good performance at school and later in society, for mental and physical health, and cognitive, social, and psychological development.

The studies performed in this subject may be ascribed to a field of neuropsychological research that attempts to demonstrate the architecture of the mind and the relation-

* Dirección para correspondencia [Correspondence address]: Sylvia Sastre-Riba. Department of Educational Sciences. University of La Rioja. C/ Luis de Ulloa, s/n (Edificio Vives), 26005, Logroño (Spain). E-mail:silvia.sastre@unirioja.es

\begin{abstract}
The ontogeny of executive functions is essential in explaining differential and normative developmental trends. Executive functions must be studied from an early age given their consequential effects on mental flexibility, monitoring information, planning, and cognitive control. We propose a differential study in alternative developmental courses through observing typical babies, Down syndrome babies, and babies with riskfactors at birth (due to low weight or to congenital hypothyroidism). Applying Systematic Observational Methodology, spontaneous babies' activity was registered. The results indicated that: a) Typical babies showed better shifting and action flexibility in order to obtain a goal, thus better results; b) Among the higher risk-babies, the lower efficacy in executive functioning was observed in underweight babies. Those with hypothyroidism were more in line with the typical babies; c) Underweight babies showed a good level of combining actions but they obtained inferior results; d) Down syndrome babies displayed more executive functioning difficulty, lower flexibility, high perseveration and less error detection.

Key words: Early development; differential trends; executive function; cognitive outcome.
\end{abstract}

ship between inhibition and the appearance of new skills relating to cognitive control and mental flexibility to solve problems. Researchers such as Diamond (1990, $1991 \mathrm{a}-\mathrm{b}$, 1998, 2013), Houdé (2000), Mounoud (1996), and Johnson (2012), have used this approach to renew the concept of early human competences in different situations such as object permanence (Diamond, 1998; Munakata, 1998), number (Houdé, 2000), or categorisation (Daurignac, Houdé, \& Jouvent, 2006). Other researchers have focused on the relationship between Executive Functions and intelligence (Crinella \& Yu, 2000; Marcovitch \& Zelazo, 2009), and the role of these functions in behavioural control.

The processes referred to as Executive Functions are associated with high-order cognitive abilities that require: holding plans or programs in mind until executed (working memory), inhibiting irrelevant action (inhibition), and planning a sequence of actions (planning). Executive Functions are related to the processes involved in their solution of tasks and the maintenance of objectives. This definition facilitates its application and suggests relatively well-defined measures (Jacques \& Zelazo, 2001; Carlson, 2005; Markovitch \& Zelazo, 2009; Diamond, 2013) to explain them. There is a general agreement that there are three core Executive Functions (Diamond, 2013): a) Inhibition, which includes inhibitory control of behaviour -self control-, and cognition -interference control, selective attention-; b) working memory; and c) cognitive flexibility or shifting. All of them are directly related to cognitive flexibility (Diamond, 2013) or perseveration.

Cognitive inhibition is defined as a control instrument that suppresses ineffective information and proactive or retroactive interference from distracting information, responses 
or representations. It is usually in the service of aiding working memory and enables the selection of relevant representations and actions within an action procedure, as well as the consequent "shifting" or efficient activation after stop-signal inhibition of a dominant action or information, enabling the use of a new strategy or the modulation of the strategy used thus far (Daurignac et al., 2006; Anderson \& Levy, 2009; Munakata et al., 2011). Therefore, a failure of inhibition of an inappropriate response leads to perseveration or impulsivity, and to inappropriate cognitive functioning, as mentioned previously. During cognitive development inhibition, resources must increase with age while perseveration decreases, indicating that inhibitory control early in life could be predictive of outcomes through life.

Working memory involves keeping information in mind and working with it. Working memory is related to inhibitory control and co-occur supporting one another (Diamond, 2013), as well as with planning as the capacity to identify and organise the steps and elements necessary to achieve an objective, analyse alternatives, make choices, maintain an objective, and remain attentive during execution. As well as the other executive processes working memory develops early from 9 months (Diamond, 1990; Nelson et al., 2013) and shows a prolonged developmental progression.

Cognitive flexibility or "shifting" entails the ability to ignore irrelevant information or tasks and focus on relevant information or tasks, prompting a change of response. Cognitive flexibility requires and builds on inhibitory control and working memory. An alteration in shifting is revealed by perseveration or repetitive and inappropriate activation of an inappropriate response, without modulation. Today, perseveration is considered to be a functional characteristic present in various types of psychopathology and development disorders normally deriving from injuries or dysfunctions in the prefrontal cortex, and it results in a failure to control inadequate responses that, in turn, affect representational rigidity (Kirkham \& Diamond, 2003) and functioning.

The prefrontal cortex has been identified as an important neurological correlate of executive functions and inhibition, although there is still much debate as to the co-participation of other areas of the brain such as the striate nodes (caudate nucleus), the anterior cingulated cortex, and the cerebellum (Lamm, Zelazo, \& Lewis, 2006). Its maturity and development depend on the temporal organisation of behaviour, including the suppression of interference (or inhibition). Specifically, the activation of inhibition as a cognitive mechanism is related to the maturity of the dorsolateral prefrontal cortex, which occurs at the age of around five months (Diamond, 1990, 1991a, 2006) and is completed by activation of the Supplementary Motor Area (at around eight months), which favours interconnection between brain hemispheres and, with it, the association of the information obtained.

Several common disorders have been associated with deficits in Executive Functions as these children tend to have less capacity to compensate in the face of other risk factors early in life (Johnson, 2012). On the other hand, be- ing at the lower end of typical variation in executive functions skills early in the life may be considered an additional risk factor due the lesser capacity to adapt in response to other perturbations to the typical development course. In contrast to the burgeoning literature on Executive Functions in preschool age children, relatively little is known about the origins of Executive Functions in infancy and its development during the first years of life (Marcovitch \& Zelazo, 2009) and there are limitations with the conclusions that can be drawn.

The results obtained thus far show the existence of changes in these functions associated with age (Zelazo, Müller, Frye, \& Markovich, 2003), the influence of different frontal cerebral lesions on their functioning, and manifestations of different intensities in the development of children with risk factors at birth (Elliott, 2003). Research remarks the importance of brain integrity for intact executive function, not only frontal regions (Anderson et al., 2010).

Therefore, any atypical brain development and specifically in the prefrontal lobes of infants, could be expected to result in significant deficits in cognitive functioning related with various neurodevelopmental disorders as: autism spectrum disorders, attention deficit hyperactivity disorder (ADHD), language disorders, and schizophrenia, as well as acquired disorders of the right brain (and traumatic brain injury) impair executive function, and the prefrontal cortex may be particularly susceptible to delayed development in these populations persistent into childhood and adolescence (Jing \& Nicholas, 2012). These manifestations are particularly interesting when they appear in pre-school age during the acquisition of basic skills and knowledge such as the control of attention, planning, the resolution and acquisition of knowledge, resistance to distractors, in premature children, children with low weight at birth, autistic children, children with ADHD, or children with frontal lesions. These dysfunctions are not predetermined but are rather the expression of the successive process of development (KarmiloffSmith, 2007) conditioned by functional differences of the brain functioning (e.g. metabolopathies or intra or extrauteral nutritional problems) or functional and structural differences (e.g. prematurity, Down's syndrome).

Children born preterm or with low birth weight are considered at-risk because their specific neuropsychology of immaturity at birth is associated with dysfunctional development outcomes. Although it is difficult to interpret the differences between born preterm and children born at term, results indicate that they show during childhood moderate to severe deficits in academic achievement, attention problems, internalising behaviour problems, and poor executive function (Weijer-Bergsma et al., 2007; Bayless \& Stevenson, 2007; Aarnoudse et al., 2009). With regards to children with congenital hypothyroidism, the influence of thyroxin hormone is proved in the neurocognitive function, especially on selective attention and outcome of ADHD during childhood (Morreale et al., 2004; Aijaz et al., 2006; Hughes et al., 2008). Among Down's syndrome babies, re- 
search shows an impairment of executive function in preschool and school years (Rowe et al., 2006, Borella et al., 2012) with global expression and, specially, in rigidity in cognitive functioning. A great deal is known about neurobiological alterations consisting of different structural and functional alterations (Ball et al., 2010) of the brain for instance, hippocampal and prefrontal (Pennington et el., 2003), that seem to be due to both problems of development (dysgenesis) and the presence of toxic factors that may impair neuronal life.

Significantly smaller total brain volume, smaller white and grey matter volume, smaller cerebellum hippocampus and corpus callosum, associated with decreased general cognitive functioning supports the importance of cerebral atypicality integrity for later executive function of preterm infants and low weight birth (de Kieve et al., 2012) comparatively to typical ones. These neuropathological pathways associated with later executive dysfunction in preterm and very preterm infants are associated with bilateral reductions of the cerebral regions: dorsolateral prefrontal cortex, sensorimotor, parieto-occipital, and premotor cortex. It shows the importance of cerebral injury and structural brain development on born preterm and or low birth weight infants. All of them are accompanied by working memory performance and executive functions (Oosterlaan, 2012; Bayleys \& Stevenson, 2007; Woodward et al., 2011; Edgin et al., 2008). More in-depth research in this area may enable important conclusions to be drawn for the improvement and optimisation of intellectual capacity.

Pursuant to the foregoing, our comparative and differential study aims to determine if there are early differences on executive functioning among typical babies, babies with risk factors at birth or babies with Down's syndrome focusing on inhibition, interference, perseveration, and "shifting" and their consequences for mental flexibility, the maintenance of an objective and the control of action.

\section{Method}

\section{Participants}

Twenty-eight $(n=28)$ babies were studied with differential development paths: a) typical babies (control group), $n$ $=10$; b) babies with pathology established at birth (babies with Down's syndrome), $n=6$; c) babies with risk factors at birth: $n=6$ babies with congenital hypothyroidism, and $n=6$ babies with low weight at birth. The typical babies were studied at the chronological age of 15 months. The babies with Down's syndrome and the babies with risk factors at birth were studied at an age of cognitive development equivalent to 15 months, according to the result of their prior evaluation using the Systematic Observation Scales of 0 to 3 years (Cambrodí \& Sastre, 1993) independently of their chronological age. The typical babies were selected from a nursery school. The babies with Down's syndrome and babies with risk factors at birth were selected in collaboration with the paediatric teams at public hospitals in La Rioja (Spain); they represent the total number of children born with these risk factors and pathology in La Rioja during the year of the participants' extraction. In all cases the participation of the babies was authorised in writing by their parents.

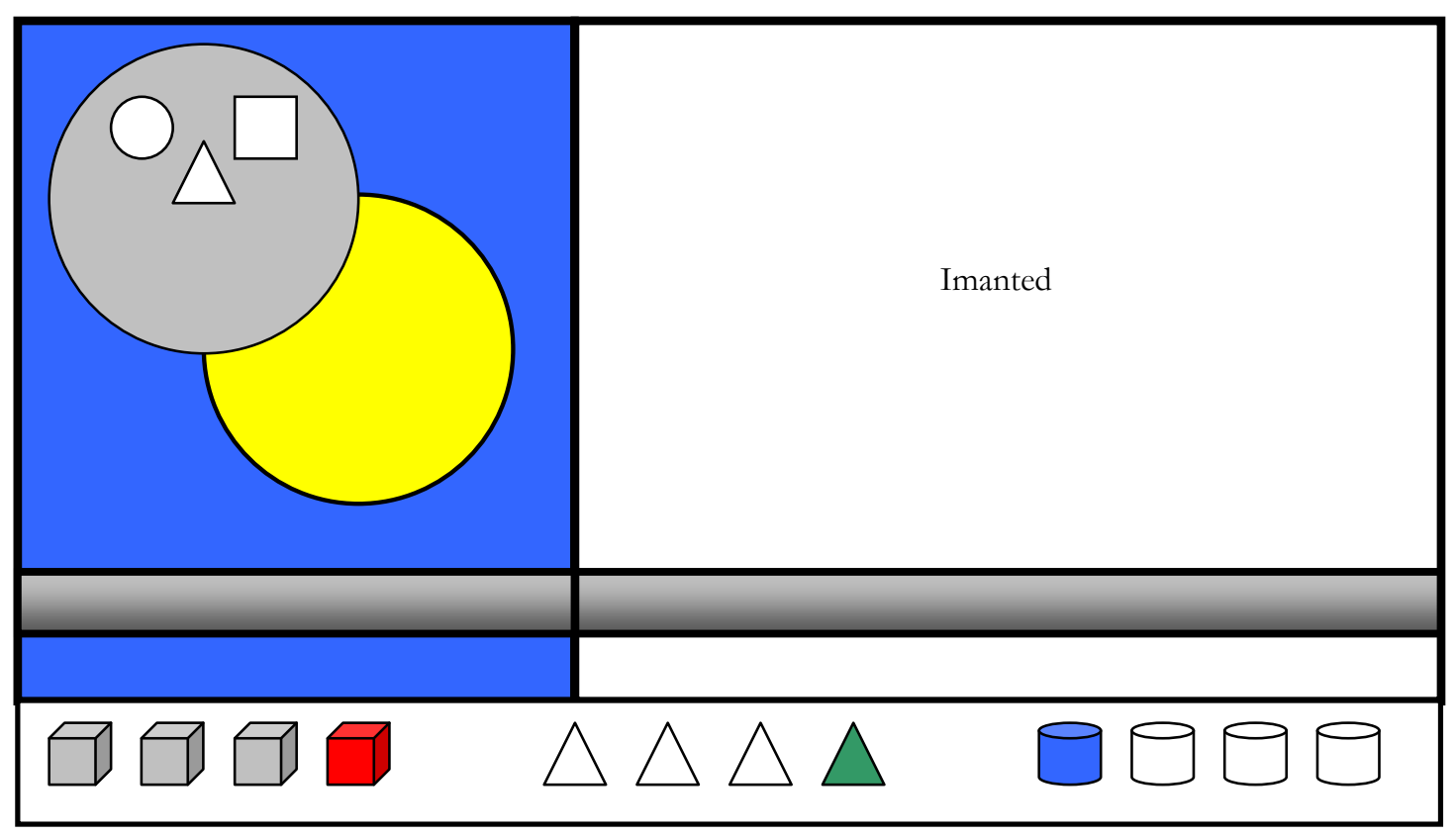

Figure 1. Materials of the study.

Note: Possible actions: Cover/uncover; Put in/put out; Throw; Hit; Group; Line; Pile; Connect/disconnect; Fit; Store. 


\section{Materials and Instruments}

The stimulus material have been validated in previous study (Sastre, 2005; Sastre, Escolano, \& Merino, 2004) and it consisted of an open non-verbal task that enabled different organised actions to be performed (to cover and uncover, to put in or put out, to hit, to group, to line, to connect or disconnect, to fit, to pile, etc.). These actions are closely related to executive functions of: planning, working memory, cognitive inhibition, and cognitive flexibility because babies in its continuum of activity must plan, sustain a goal, modulate action schemes, detect errors, inhibition non-pertinent information or schemes, and reconsider the activity displayed, i.e, cognitive flexibility (see Figure 1).

\section{Procedure}

The spontaneous activity of the 15 month old babies with the stimulus material was recorded for an average period of 15 minutes. The babies sat opposite the material and next to an adult (after they had become familiar with the adult) who was instructed only to intervene: a) if directly requested by the baby; b) if the baby became inactive; or c) if the baby performed are repetitive action. The typical babies were recorded at the nursery school they attended on a daily basis. The other babies were recorded at San Pedro Hospital (La Rioja, Spain), where they were monitored. In both cases, monitoring was performed in rooms familiar to the babies and without distracting stimuli. In order to understand the participation of executive functions in the differential actions of babies, it was necessary to: 1) obtain information on the dynamics and importance of individual executive functioning to compare the different groups; 2) determine the underlying executive structure from the actions performed through behavioural units; and 3) understand the phenomenon studied in the natural continuum in which it occurred.

For this purpose, several analyses were designed (SastreRiba, 2005; Sastre-Riba et al., 2004). There are two levels gradually enabled greater abstraction from the empirical reality from which the data were obtained to quantification and statistical analysis.

First level. This level consisted of a microanalysis of the continuum of activity: a) the transcription of the children's actions; b) the selection of the analysis system; and c) data quality control (Sastre-Riba et al., 2004; Sastre-Riba, 2005, 2006). Infant behaviour was reduced according to the underlying executive structures on categories. All of them related to executive functions in order to infer them from the infants' actions. This mixed analysis system, previously validated (Sastre et al., 2004, 2007; Blanco et al., 2010), was around nine categories shown in Table 1 , relating to infant executive functioning of: cognitive inhibition, cognitive flexibility or shifting, working memory, in a positive sense (good executive function) or in a negative sense (non efficient executive function).
The quality of executive functioning was determined from the different behavioural units comprising each baby's activity. Mental flexibility was deduced from the onset of selected behavioural units (content) in the child's activity, and was classified as either positive (indicator of flexibility) or negative (indicator of lower flexibility, or rigidity). The specific indicators of cognitive flexibility were SH1, SH2, AUC, COM, optimally associated with RE. The indicators of lower flexibility were deduced from the absence or lower frequency of these indicators, combined with the appearance of ACT. The indicators of working memory were AUC, COM, and MIS. Effective cognitive inhibition was associated with cognitive flexibility indicators: SH1, SH2, AUC, and ineffective inhibition were associated with: DET, MIS, ACT. The other behavioural units associated with the higher or lower frequency of flexibility indicators and used to determine the type of executive functioning were: MIS, NES, RE, and DET. Empirical examples of this mixed analysis system of nine categories are shown in Table 2.

Table 1. Executive Function: Micro-categories.

\section{Cognitive inhibition}

$\mathbf{S H} 2=$ New action to obtain the same objective during a subsequent activity

SH1 = Change the objective during the course of the activity

$\mathbf{A C T}=$ Action or scheme repetition (without modulations). Perseveration

\section{Cognitive Flexibility}

DET $=$ Stopping the activity

MIS $=$ Non-immediate action repetition

NES $=$ New scheme not observed during the course of activity

AUC = Alter an error/goal maintenance to try a new resolution

$\mathbf{C O M}=$ Mapping different actions to obtain an objective

Result

$\mathbf{R E}=$ Stable product of the mapping of actions

To ensure the reliability of the process, data quality controls were performed on the transcription and encoding of the previously randomised observation units (audio visual recordings). For this purpose, the degree of inter- and intraobserver concordance was calculated as follows:

a) Selection of strata using the "Aleatori" programme (Vargas, 1999). One stratum corresponded to each of the temporal fragments into which each recording session could be divided. These divisions corresponded to the initial, intermediate and final block of a recording or register. Fiveminute temporal strata were established for each subject and session: The initial block from minutes 1 to 5 ; the intermediate block from minutes 5 to 10 ; and the final block from minutes 10 to 15 ; and

b) Calculation of Krippendorf's inter- and intra-observer coefficient. Inter-observer calculation was performed with the collaboration of 2 experts. Intra-observer evaluation was carried out with a temporal interval of 20 days between the first transcription and encoding and the second. After controlling data quality and determining the interand intra-observer concordance indices (.83 and .86), 
which were satisfactory, we then transcribed and encoded all the activity registers.

Second level: Encoding and quantification of behavioural units. This analysis enabled us to determine significant dif- ferences in executive functioning between the groups studied. Since the samples studied were small, the differences between them were calculated using the Mann-Whitney U test.

Table 2. Examples of behavioral units.

SH2 New action to obtain the same objective during a subsequent activity [Tries to put the triangle into the slot in the recipient by repeatedly hitting it against the top but does not manage to fit it in; then turns the hand with the triangle in it, managing to fit the object into the recipient].

SH1 Change of objective during the course of the activity [Puts the triangle into the slot in the recipient; then connects a triangle and a cylinder together].

AUC Alter error/goal maintenance to try a new resolution [Tries to put the triangle into the slot of the recipient by repeatedly hitting it against the top but does not manage to fit it in; then turns their hand and in doing so manage to fit the triangle into the slot].

.CO Mapping different actions to obtain an objective [Puts a cylinder into the slot of the recipient [first action], connects another two cyl-

$\mathbf{M}$ inders [second action], and fits it in by connecting cylinders together].

NES New scheme not observed during the course of activity [Sets the blocks down on a flat surface, lining them up in groups; then connects a triangle and a cube together].

MIS Non-immediate action repetition [Fits a cube into the recipient; picks up a triangle and puts it into the recipient; picks up a triangle and fits it into the recipient].

RE Stable product of the mapping of actions. [Piles all the blocks into the recipient storing them one by one [aim is to fill up the recipient]; then closes the recipient with the lid].

ACT Action or scheme repetition (without modulation). Perseveration [Picks up a triangle and throws it onto the floor; picks up a triangle and throws it onto the floor; picks up a triangle and throws it onto the floor].

DET Stopping the activity [Connects blocks together and puts them out onto the recipient. Stops action and returns, abandoning the activity].

\section{Results}

Table 3 shows the raw frequencies in the appearance of the different behavioural units of the different study groups. These results enable us to determine whether or not the groups had comparable levels of executive functioning. They also allow us to locate the behavioural units and classify it

Table 3. Raw frequencies in the microcategories.

\begin{tabular}{lcccc}
\hline \multirow{2}{*}{$\begin{array}{l}\text { Micro- } \\
\text { categories }\end{array}$} & $\begin{array}{c}\text { Bow-birth } \\
\text { Typical }\end{array}$ & $\begin{array}{c}\text { Hypo- } \\
\text { weight }\end{array}$ & $\begin{array}{c}\text { Down- } \\
\text { thyroidism } \\
\text { syndrome }\end{array}$ \\
\hline SH2 & 48 & 34 & 31 & 12 \\
SH1 & 37 & 16 & 10 & 38 \\
ACT & 0 & 3 & 8 & 4 \\
DET & 11 & 6 & 4 & 8 \\
MIS & 120 & 16 & 9 & 73 \\
NES & 10 & 11 & 6 & 6 \\
AUC & 13 & 15 & 22 & 3 \\
COM & 40 & 6 & 12 & 1 \\
RE & 16 & 4 & 13 & 4 \\
\hline
\end{tabular}

Note: $\mathrm{SH} 2$ = New action to obtain the same objective during a subsequent activity; $\mathrm{SH} 1$ = Change the objective during the course of the activity; ACT $=$ Action or scheme repetition (without modulations); DET $=$ Stopping the activity; MIS = Non-immediate action repetition; NES $=$ New scheme not observed during the course of activity; AUC = Alter an error/goal maintenance to try a new resolution; $\mathrm{COM}=$ Mapping different actions to obtain an objective; $\mathrm{RE}=$ Stable product of the mapping of actions

positively or negatively as an indicator of greater or less flexibility and executive functioning between the different groups: typical babies, babies with Down syndrome, hypothyroid babies and babies with low weight.
Table 4 helps us identify the statistically significant differences between the groups compared and the groups in which these are more or less frequent the behavioural units. It is useful to identify the groups that achieved the most positive results overall at the age of 15 months in terms of executive functions relating to flexibility (shifting, autocorrection, combination) $\mathrm{SH} 2, \mathrm{AUC}, \mathrm{COM}$ and achievement of objectives (results) RE, or those relating to less flexibility and, therefore, closer to cognitive rigidity (same action) MIS, (perseveration) ACT with its relevant consequences.

As the results show, at 15 months there were statistically significant differences between the different groups of babies studied in the following units: SH2, RE, COM. Since the differences were observed between all the groups, the group displaying a sustained difference with respect to all the other groups was the most flexible, in this case the typical babies. Another difference repeated in practically all the groups was that of perseveration (ACT); the babies with Down syndrome presented the highest levels of perseverations. This characteristic, coupled with their lower flexibility, prompted us to deduce that their efficient use of executive mechanisms was below that of the other groups.

The typical babies were the most flexible ( $\mathrm{SH} 2, \mathrm{RE}$, $\mathrm{COM}$ ) since they displayed a larger number of changes of strategy to achieve objectives, more results and greater integration of strategies. They were followed by the group of babies with hypothyroidism and these were in turn followed by the babies with low weight. Differences were also observed among the groups with risk factors. The hypothyroid babies were the most flexible, although the babies with low weight were significantly ahead of the babies with Down syndrome. Moreover, the typical babies did not display any 
perseveration, indicating more efficient inhibition with respect to the other groups.

The babies with Down syndrome executed the smallest number of executive mechanisms relating to mental flexibility. They obtained more results than the babies with low weight, but they were repetitive and persevering actions. In terms of the two groups of babies with risk factors at birth, we observed once again that the hypothyroid babies pre- sented better executive functioning. Table 5 presents a summary of the significant differences between the different groups. The group of typical babies presented the greatest flexibility, followed by the hypothyroid babies. The most perseverant and "rigid" group was the one formed by babies with Down syndrome. As regards the babies in the risk group, the group of babies with low weight tended to display less effective executive functioning (see Figure 2).

Table 4. Intergroup differences: Typical, Down's syndrome, Low Birth Weight, and Hypothyroidism groups of babies aged 15 months.

\begin{tabular}{|c|c|c|c|c|c|c|}
\hline \multirow[b]{2}{*}{ Micro-categories } & \multicolumn{6}{|c|}{ Comparison Groups } \\
\hline & T vs DS & T vs LBW & T vs $\mathrm{H}$ & DS vs LBW & DS vs H & LBW vs $\mathrm{H}$ \\
\hline $\mathrm{SH} 2$ & $\mathrm{~T}^{* *}$ & LBW* & $\mathrm{T}^{*}$ & $\mathrm{LBW}^{* *}$ & $\mathrm{H}^{*}$ & $\mathrm{H}^{*}$ \\
\hline SH1 & & & & & & \\
\hline $\mathrm{ACT}$ & DS** & $\mathrm{LW}^{* *}$ & $\mathrm{H}^{*}$ & & DS* & \\
\hline DET & & & & $\mathrm{LBW}^{*}$ & & $\mathrm{LBW}^{*}$ \\
\hline MIS & & & & & & $\mathrm{H}^{*}$ \\
\hline NES & & $\mathrm{T}^{*}$ & & $\mathrm{~W}^{* *}$ & $\mathrm{H}^{*}$ & $\mathrm{H}^{*}$ \\
\hline AUC & $\mathrm{T}^{* *}$ & & $\mathrm{H}^{*}$ & LBW* & $\mathrm{H}^{*}$ & $\mathrm{H}^{*}$ \\
\hline $\mathrm{COM}$ & $\mathrm{T}^{* *}$ & $\mathrm{~T}^{* *}$ & $\mathrm{~T}^{*}$ & $\mathrm{LBW}^{* *}$ & $\mathrm{H}^{*}$ & $\mathrm{H}^{*}$ \\
\hline RE & $\mathrm{T}^{* *}$ & $\mathrm{~T}^{* *}$ & $\mathrm{~T}^{*}$ & $\mathrm{D}^{*}$ & $\mathrm{H}^{*}$ & $\mathrm{H}^{*}$ \\
\hline
\end{tabular}

$* p<.05 ; * * p<.01$

Note: $\mathrm{T}=$ Typical; DS = Down syndrome; LBW = Low birth weight; $\mathrm{H}=$ Hypothyroidism

$\mathrm{SH} 2=$ New action to obtain the same objective during a subsequent activity; SH1 $=$ Change the objective during the course of the activity; ACT $=$ Action or scheme repetition (without modulations); DET = Stopping the activity; MIS = Non-immediate action repetition; NES = New scheme not observed during the course of activity; AUC = Alter an error/goal maintenance to try a new resolution; $\mathrm{COM}=$ Mapping different actions to obtain an objective; RE = Stable product of the mapping of actions.

Table 5. Intergroup statistically significant differences.

\begin{tabular}{|c|c|c|c|c|c|c|c|}
\hline & Shifting & Autocorrection & Result & Combination & New action & Same action & Perseveration \\
\hline+ & $1 \& 2 \& 3$ & $1 \& 2$ & $1 \& 2$ & 1 & 4 & 4 & 4 \\
\hline- & 4 & 4 & $4 \& 3$ & $4 \& 3$ & 3 & - & 1 \\
\hline
\end{tabular}

Note: 1 = Typical babies; 2 = Hypothyroidism babies; 3 = Low birth weight babies; 4 = Down syndrome babies.

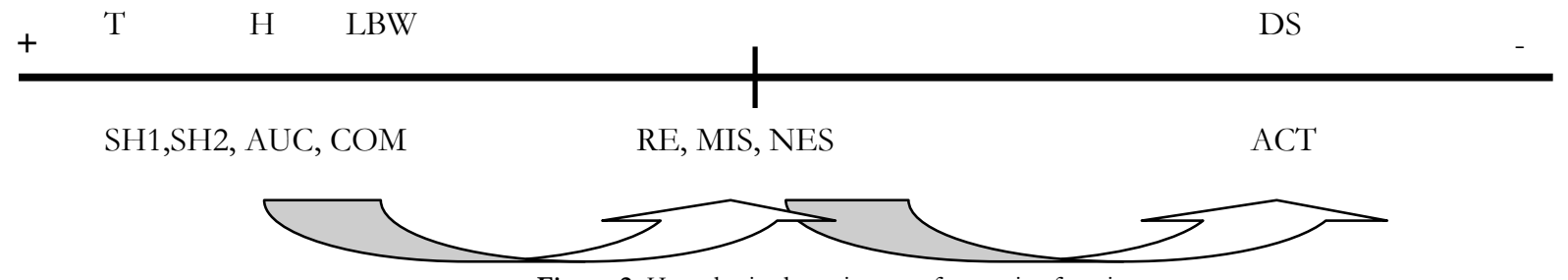

Figure 2. Hypothesised continuum of executive functions.

Note: $\mathrm{T}=$ Typical DS = Down syndrome; LBW = Low birth weight $\mathrm{H}=$ Hypothyroidism; $\mathrm{SH} 2=$ New action to obtain the same objective during a subsequent activity; SH1 = Change the objective during the course of the activity; ACT = Action or scheme repetition (without modulations); DET = Stopping the activity; MIS = Non-immediate action repetition; NES = New scheme not observed during the course of activity; AUC = Alter an error/goal maintenance to try a new resolution; $\mathrm{COM}=$ Mapping different actions to obtain an objective; $\mathrm{RE}=$ Stable product of the mapping of actions.

\section{Discussion and conclusions}

The results not only show the existence of a differential gradient in early executive functioning but also the differences that appear in each group studied.

The differential gradient in early executive functioning is interesting in that it show us the proficiency of each developmental group within it. As can be observed, the best executive functioning corresponds to the typical babies, with the Down's syndrome babies found situated at the other extreme of the gradient, representing the group with the most executive difficulties. It is interesting to see that the congenital hypothiroidism group is that most in line with the typical babies' functioning, followed by the low weight birth babies; all of which can be found on the positive gradient. The differences found in early executive functioning have therefore been revealed, and allow us to place the developmental groups studied in a gradient from best to worst performance.

Belonging to groups with different risk factors was thus important in explaining the difference in executive functioning. Although babies with low weight displayed good execu- 
tive functioning indicators, they displayed poorer characteristics in others, such as: a) difficulties to change action strategies to achieve a goal, and b) lower levels on obtaining results and on combining actions to achieve them. Overall, perseveration is present and consequently there is less flexibility.

Among the babies with risk factors, the hypothyroidism group displayed better executive functioning, specifically in relation to shifting, action combination to achieve a goal, action modulation, error detection and auto-correction. Perhaps the hormone replacement therapy they receive from the neonatal period has a positive impact on their cerebral metabolism and structure (Hughes et al., 2008). The babies with Down syndrome, despite displaying the lowest executive efficiency (highest level of perseveration and the lowest level in combining actions to achieve a goal), they also displayed quite positive levels in the obtainment of results and shifting, a characteristic which should help them optimise these early manifestations of executive control.

Among the differences detected, the most important were: a) the selective activation; and, b) the inhibition of the non-pertinent actions, both in order to obtain a goal, i.e., shifting. The least efficiency was observed in Down's syndrome babies, who displayed repetition in their actions and the poorest flexibility. One can hope that the impact of these effects on their cognitive development do so atypically.

\section{References}

Aarnoudse-Moems, C. S. H., Weiples-Kuperus, N., Bernard van Goudoever, B., \& Oosterlaam, J., (2009). Meta-Analysis of Neobehavioral Outcomes in Very-Preterm and/or Very Low Birth Weight Children. Pediatrics, 124, 717-728.

Aijaz, N., Flaherty, E. M., Bracken, S. S., Lane, A.H., \& Wilson, Th. A., (2006). Neurocognitive function in children with compensated hypothyroidism: lack of short term effects on or of thyroxin. BMC Endocrine Disorders, 6 (2).

Anderson, M. C., \& Levy, B. (2009). Suppressing unwanted memories. Current Directions on Psychological Science, 18, 189-194.

Anderson, M. C., Spencer-Smith, M., Coleman, L., Anderson, P., Williams, J., Greenkam, M., Leventer, R.J., \& Jacobs, R. (2010). Children's executive functions. Are they poorer after very early brain insult? Neuropsychologia, 48, 2041-2050.

Ball, S. L., Holland, A. J., Watson, P. C., \& Huppert, F.A. (2010). Theoretical exploration of the neural basis of behavioural desinhibition, apathy and executive dysfunction in preclinical Alzeimer's disease in people with Down's syndrome: potential involvement of multiple subcortical circuits. Journal of Intellectual Disabilities Research, 54, 320-336.

Bayless, S., \& Stevenson, J. (2007). Executive functions in school-age children born very prematurely. Early Human Development, 83, 247-254.

Blair, C., Zelazo, P. D., \& Greenberg, M. (2005). The assessment of executive function in early childhood: prospects and progress. Developmental Neuropsybology, 28, 561-571.

Blanco, A., Sastre, S., \& Escolano, E. (2010). Desarrollo ejecutivo temprano y Teoría de la Generalizabilidad: bebés típicos y prematuros [Executive function in early childhood and Generalizability Theory: Typical babies and preterm babies]. Psicothema, 22, 221-226.

Borella, E., Carretti, B., \& Lanfranchi, S. (2012). Inhibitory mechanisms in Down syndrome: Is there a specific or general deficit? Research in Developmental Disabilities, 34, 65-71.

Cambrodí, A., \& Sastre, S. (1993). Escales d' Observació Sistemática 0-3 anys. Barcelona: PPU.
To summarise, the results obtained corroborate other differential studies on early executive development (e.g., Aarnadouse et al., 2009; Aijaz et al., 2006; Borella et al., 2012; Jing \& Nicholas, 2012), demonstrating the importance of studying executive functions in such early stages of development (Karmiloff-Smith, 2007) as these functions determine future functioning development and may explain executive differences and/or difficulties (Kirkham \& Diamond, 2003) from a neuroconstructivist framework.

In order to develop these results, the study sample should be increased to compare and /or corroborate these findings. Moreover, a longitudinal study should be designed to determine whether these executive differences are maintained throughout development and to identify the manifestations and differential consequences of these functions and their crystallization in learning behaviour and emotional control throughout childhood. It would also be useful to determine whether the incipient intergroup differences are maintained overtime. Results could improve early educational intervention in order to optimize the developmental success. Despite the limitations, the current findings provide empirical support to early intervention professionals in order to enhance the educational activities looking forward their developmental optimization.

Carlson, S. M. (2005). Developmentally sensitive measures of executive function in preschool children. Developmental Neuropsychology, 28, 595616.

Crinella, F. M., \& Yu, J. (2000): Brain mechanisms and intelligence. Psychometric $g$ and executive function. Intelligence, 27, 299-327.

Daurignac, E., Houdé, O. \& Jouvent, R. (2006). Negative priming in a numerical Piaget-like task as evidenced by ERP. Journal of Cognitive Neuroscience, 18, 730-736.

De Kieve, J. F., van Elburg, R. M., Vermenlen, R. J., \& Oosterlanan, J. (2012). Brain development of very preterm and very low-birth weight children in childhood and adolescence: a metanalysis. Developmental Medical Child Neurology, 54, 313-323.

Diamond, A. (1990). The development and neural basis of higher cognitive functions. New York: New York Academy of Sciences Press.

Diamond, A. (1991a). Neuropsychological insights into the meaning of object concept development. In S. Carey, \& R. Gelman (Eds.), The epigenesis of mind: Essays on biology and cognition (pp. 67-110). Hillsdale, NJ: Lawrence Erlbaum Associates.

Diamond, A. (1991b). Frontal lobe involvement in cognitive changes during the first year of life. In K.R. Gibson \& A.C. Petersen (Eds.), Brain maturation and cognitive development: Comparative and cross-cultural perspective (pp. 67-110). New York, NY: Aldine de Gruyter.

Diamond, A. (1998). Understanding the A-non B error: working memory versus reinforced response or active trace versus latent trace. Developmental Science, 1, 185-189.

Diamond, A. (2006). The Early Development of Executive Functions. In E. Bialystock \& F. I. M. Craik (Eds.), Lifespan Cognition. Mechanisms of Change, (pp. 9970-9995). New York: Oxford University Press.

Diamond, A. (2013). Executive Functions. Annual Review of Psychology, 64, 135-168.

Edgin, J. O., Inder, T. E., Anderson, P. J., Hood, K. M., Clark, C. A. A. \& Woodward, L. J. (2008). Executive functioning in preschool children born very preterm: Relationship with early white matter pathology. Journal of the International Neuropsychological Society, 14, 90-101. 
Elliott, R. (2003). Executive functions and their disorders. British Medical Bulletin, 65, 49-59.

Gioia, G. A., Isquith, P. K., \& Espy, K. (2003). Construct validity of the behavior rating inventory of executive function. Preschool version. Journal of the International Neuropsychological Society, 9, 297-306.

Houdé, O. (2000). Executive performance/competence and Inhibition in Cognitive Development: Object, number, Categorization and reasoning. Developmental Science, 2, 273-275.

Hughes, D. H., \& Bryant, J. (2008). The assessment of Cognitive Performance in Children: Considerations for detecting nutritional Influences. Nutrition Reviews, 12, 413-422.

Jacques, S., \& Zelazo, P. D. (2001). The Flexible Item Selection Task (FIST): a measure of executive function in preschoolers. Developmental Neuropsychology, 20, 573-591.

Jing, S., \& Nicholas, B. (2012). Early executive function deficit in preterm children and its association with neurodevelopmental disorders in childhood: a literature review. International Journal of Adolescent Medicine and Health, 24, 191-280.

Johnson, S. P. (2003). The nature of cognitive development. Trends in Cognitive Sciences, 7, 102-104

Johnson, M. H. (2012). Executive function and developmental disorders: the flip side of the coin. Trends in Cognitive Sciences, 16, 454-457.

Karmiloff-Smith, A. (2007). Atypical epigenesis. Developmental Science, 10, 84 88.

Kirkham, N. Z., \& Diamond, A. (2003). Sorting between theories of perseveration:performance in conflict tasks requires memory, attention and inhibition. Developmental Science, 6, 474-476.

Lamm, C., Zelazo, P. D., \& Lewis, M. D. (2006). Neural correlates of cognitive control inchildhood and adolescence: disentangling the contributions of age and executive function. Neuropsychology, 44, 2139-2148.

Marcovitch, S., \& Zelazo, P. D. (2009). A hierarchical competing systems model of the emergence and early development of executive function. Developmental Science, 12 (1), 1-25.

Morreale de Escobar, G., Obregón, M.J., \& Escobar del Rey, F. (2004). Role of thyroid hormone during early brain development. European Journal of Endocrinology. 151 (3), 25-37.

Mounoud, P. (1996). A recursive transformation of central cognitive mechanisms: The shiftfrom partial to whole representation. In A.J. Sameroff \& M. M. Haith (Eds.), The five to seven year shift: The age of reason and responsibility (pp. 85-110). Chicago: Chicago University Press.

Munakata, Y. (1998). Infant perseveration and implications for object permanence theories: APDP model of de "A- non-B" task. Developmental Science, 1, 161-211

Munakata, Y., Herd, S. A., Chatham, C. H., Dagne, B. E., Banich, M. T. \& Reilly, R. C. (2011). A unified framework for inhibitory control. Trends of Cognitive Science, 15, 453-459.

Nelson, J. M., Sheffield, T. D., Chevalier, N., Clark, C. A. C. \& Espy, K. A. (2013). Psychobiology of executive function in early development. In P. McCardle, L.Freun, J.A.Griffin. (Eds.), Integrating Measurement, Neurode- velopmental and Transitional Research. Washington DC: American Psychological Association.

Oosterlaan, J. (2012). Brain development of very preterm and very low-birth weight children in childhood and adolescence: a meta-analysis. Developmental Child Neurology, 54, 313-323.

Pennington, B. F., Moon, J. Edgin, J., Stedron, J. \& Nadel, L. (2003). The neuropsychology of Down Syndrome: evidence for hippocampal dysfunction. Child Development, 74, 75-93.

Rowe, J., Lavender, A., \& Turk, V. (2006). Cognitive executive function in Down's syndrome. British Journal of Clinical Psychology, 45 (1), 5-17.

Sastre-Riba, S. (2005). Tutoring Adjustment and Cognitive Gain. In, L. Anolli, S. Duncan, M.S. Magnusson, G. Riva (Eds.), The Hidden Structure of Interactions: From Neurons to Culture Patterns (pp. 196-206). Amsterdam: IOS Press.

Sastre-Riba, S. (2006) Condiciones tempranas del desarrollo y el aprendizaje: el papel de las funciones ejecutivas. Revista Neurología, 42 (s2), 143-151.

Sastre-Riba, S., Escolano, E., \& Merino, N. (2004). Observación sistemática en la cognición temprana: funciones ejecutivas, lógica e interacción. $M e-$ todología de las Ciencias del Comportamiento, 5, 557-566.

Sastre-Riba, S., Merino-Moreno, N. B., \& Escolano-Pérez, E. (2007). Formatos interactivos y funciones ejecutivas en el desarrollo temprano. Revista de Neurología, 44 (s2), 61-65.

Soprano, A. M. (2003). Evaluación de las funciones ejecutivas. Revista de Neurología, 37, 44-50.

Sylvester, C. Y. C., Wager, T. D., Lacey, S. C., Jonides, J., Smith, E. E., Hernández, L. \& Nichols, T. E. (2003). Switching attention and resolving interference: fMRI measures of executive functions. Neuropsychologia, 41 , 357-370.

Styles, J., Moses, P., Passarotti, A., \& Dick, Fr. (2003). Exploring developmental change in the neural bases of higher cognitive functions. The promise of Functional Magnetic Resonance Imaging. Developmental Neuropsychology, 24, 641-668.

Zelazo, P. D., Müller, U., Frye, D., \& Marcovitch, S. (2003). The development of executive function in early childhood. Monographs of the Society for Research in Child Development, 68, Serial No.274

Vargas, J. D. (1999). Modalidades sociocognitivas de construcción del saber en la interacción entre iguales en las primeras edades. Tesis doctoral no publicada. Universitat Rovira i Virgili, Tarragona.

Weijer-Bergsma, E., Wijnroks, L., \& Jongmans, M.J. (2007). Attention development in infants and preschool children born preterm: A review. Infant Behavior \& Development, 31, 333-351.

Westermann, G., Mareschal, D., Johnson, M., Sirios, S., Spratling, M. W. \& Thomas, M. S. C. (2007). Neuroconstructivism. Developmental Science, 10, 75-83.

Woodward, L. J., Pritchard, V. E., Anderson, P. J. \& Inder, T. E. (2011) Neonatal white matter abnormalities predict global executive function impairment in children born very preterm. Developmental Neuropsyhology, $36,22-41$.

(Article received: 01-08-2013; revised: 10-03-2014; accepted: 01-04-2014) 